\title{
Obesity increases free thyroxine proportionally to nonesterified fatty acid concentrations in adult neutered female cats
}

\author{
D C Ferguson, Z Caffall and M Hoenig \\ Department of Physiology and Pharmacology, College of Veterinary Medicine, University of Georgia, Athens, Georgia 30602, USA \\ (Requests for offprints should be addressed to M Hoenig; Email: mhoenig@uga.edu) \\ (D C Ferguson is now at Department of Veterinary Biosciences, The University of Illinois at Urbana-Champaign, Urbana, Illinois 61802, USA)
}

\begin{abstract}
The obese cat is a model for the study of the progression toward type 2 diabetes. In this study, the impact of obesity on the hypothalamic-pituitary-thyroid axis was examined in 21 domestic shorthair cats before and after the development of obesity, which significantly increased body mass index (BMI), $\%$ body fat $(\mathrm{BF})$, and girth $(P<0 \cdot 0001$ for all). Serum total thyroxine $\left(\mathrm{TT}_{4}\right)$, tri-iodothyronine, free $\mathrm{T}_{4}\left(\mathrm{FT}_{4}\right)$ by direct dialysis, nonesterified fatty acids (NEFA), and leptin were measured, and $\mathrm{FT}_{4}$ fraction $\left(\mathrm{FFT}_{4}\right)$ was calculated. Serum thyrotropin (TSH) concentrations were measured in nine animals by validating a heterologous canine TSH assay with recombinant feline $\mathrm{TSH}$ as a standard. $\mathrm{FT}_{4}, \mathrm{FFT}_{4}, \mathrm{NEFAs}$, and leptin were significantly higher in obese cats. $\mathrm{FT}_{4}$ had the strongest positive correlation with obesity indices BF, BMI,
\end{abstract}

girth, NEFA, and leptin. Fatty acids oleate and palmitate were shown to inhibit $\mathrm{T}_{4}$ binding to pooled cat serum in vitro, suggesting the possibility that this mechanism was also relevant in vivo. Serum $\mathrm{TT}_{4}$ and TSH did not rise significantly. The implications for thyroid hormone (TH) action are not yet clear, but fatty acids have been proposed to inhibit the cellular uptake of $\mathrm{TH}$ and/or pituitary $\mathrm{TH}$ receptor binding, leading to $\mathrm{TH}$ resistance. Increased leptin may also alter sensitivity to negative feedback of TH. In conclusion, feline obesity is associated with a significant increase in $\mathrm{FT}_{4}$ within the normal range; future investigation into the cellular thyroid status will be necessary to establish cause and effect in this obesity model.

Journal of Endocrinology (2007) 194, 267-273

\section{Introduction}

Cats are one of the few model species of human type 2 diabetes in which the progression towards the diabetic state can be studied longitudinally. They are the only non-primate species to develop $\beta$-cell deposits of the hallmark $\beta$-cell protein of human type 2 diabetes mellitus, amyloid (Hoenig et al. 2000). Thyroid hormones (THs) are involved in the regulation of metabolism, and regulate resting metabolic rate, thermogenesis, and lipolysis (Oppenheimer et al. 1991, Silva 1995). However, studies of thyroid function in obese people have produced inconsistent results. Obesity has resulted in either no changes in thyroid-stimulating hormone (TSH) or $\mathrm{TH}$ concentrations in the hands of some investigators (Glass \& Kushner 1996, Roti et al. 2000), a moderate rise in total and free tri-iodothyronine $\left(\mathrm{T}_{3}\right)$ and TSH serum concentrations (Bray et al. 1976, Matzen et al. 1989, Stichel et al. 2000, Reinehr \& Andler 2002), or an increase in total thyroxine $\left(\mathrm{TT}_{4}\right)$ and TSH (Iacobellis et al. 2005). A study of over 6000 human patients established a positive correlation between body mass index (BMI) and serum TSH concentrations (Nyrnes et al. 2006). Some studies are confounded by an underlying incidence of overt or subclinical hypothyroidism, as reflected by the observation of a low free $\mathrm{T}_{4}\left(\mathrm{FT}_{4}\right)$ and high
TSH concentration (Knudsen et al. 2005), or low total $\mathrm{T}_{3}$ $\left(\mathrm{TT}_{3}\right)$ and $\mathrm{TT}_{4}$ with increased $\mathrm{TSH}$ and thyroid volume, suggesting a primary disruption of $\mathrm{TH}$ synthesis (Sari et al. 2003). A progressive increase in serum $T_{3}$ concentration and a concomitant fall in reverse $\mathrm{T}_{3}$ concentration have also been observed (Davidson \& Chopra 1979).

Clinical studies of spontaneous obesity in dogs have resulted in similar discrepancies: in a case study of 31 obese canine patients, $58 \%$ had results consistent with overt or equivocal primary hypothyroidism (Martin et al. 2006). In another study, serum $\mathrm{TT}_{4}$ and $\mathrm{T}_{3}$ concentrations were higher but only $\mathrm{T}_{3}$ decreased with food restriction (Daminet et al. 2003).

It has been suggested that the cause of the increased serum $\mathrm{TH}$ concentrations together with an increase in TSH might be caused by hypothalamic-pituitary-TH resistance (Edupuganti et al. 1997). Supporting this hypothesis is the observation that $T_{3}$ receptors are decreased in obesity and the negative feedback of circulating THs on TSH is decreased (Burman et al. 1980). Several studies have tried to establish a link between TH and leptin on energy expenditure; however, others have shown that the action of leptin was not dependent on the presence of TH (Vettor 2005).

Despite the variety of prior studies, none have ascertained the mechanism of the increase in free and/or total $\mathrm{TH}$ 
concentrations in obesity. Most studies in man have been in spontaneously obese patients and interpretation has been complicated by the uncertainty of the underlying incidence of subclinical hypothyroidism. Cats are not prone to the development of spontaneous adult onset hypothyroidism to the extent of man or dog, having only a small incidence of congenital disease (Tobias \& Labato 2001). We have previously shown that obese cats have decreased heat production and changes in fat metabolism (Hoenig et al. 2007a,b), raising the possibility that alterations in fat mass may impact hypothalamicpituitary-thyroid axis function as well as calorigenesis. Therefore, in this study, we sought to study lean euthyroid cats before and again after the development of stable obesity to identify potential effects on the hypothalamic-pituitary-thyroid axis.

\section{Materials and Methods}

\section{Animals}

Twenty-one adult (aged 1-2 years) neutered purpose-bred female cats (Sinclair, Columbia, MO, USA and Harlan SpragueDawley, Madison, WI, USA) were used. All cats were maintained at the University of Georgia College of Veterinary Medicine Animal Care Facility, using standard colony conditions. Cats were housed separately in cages and were provided unlimited access to water. Animal studies were approved by the University of Georgia Animal Care and Use Committee and conducted in accordance with the guidelines established by the Animal Welfare Act and the National Institutes of Health. It was determined that the cats were healthy on the basis of results of physical examination and clinical laboratory tests. All cats were used to being handled daily. All cats were fed a commercially available diet (Iams Ocean Fish and Rice, Dayton, OH, USA) once daily and food intake was recorded at each feeding. Their weight was monitored weekly. BMI and \% fat mass were measured as described (Hoenig et al. 2003) at the beginning of the study and after the cats had gained $\sim 40 \%$ of fat mass. At both time points, blood was drawn, allowed to clot, and serum was collected after centrifugation at $500 \boldsymbol{g}$ for $10 \mathrm{~min}$. The serum was stored at $-20^{\circ} \mathrm{C}$ until assayed.

\section{TH and NEFA assays}

Serum $\mathrm{TT}_{4}$ and $\mathrm{TT}_{3}$ were measured by previously described and validated procedures using in-house RIAs with commercially prepared antibodies (Endocrine Sciences, Tarzana, CA, USA) as described previously (Peterson et al. 1983, Ferguson \& Peterson 1992). Free $\mathrm{T}_{4}\left(\mathrm{FT}_{4}\right)$ concentrations were measured by direct dialysis using the Nichols Institute (San Juan Capistrano, CA, USA) kit. Leptin was measured using the Linco multi-species leptin ELISA as validated for cats (Hoenig et al. 2003). Nonesterified fatty acids (NEFAs) were measured using an enzymatic test kit (Wako Diagnostic, Richmond, PA, USA). In the cats, the $\mathrm{FT}_{4}$ fraction expressed as a percentage was calculated as: $\% \mathrm{FT}_{4}=\mathrm{FT}_{4}$ concentration $(\mathrm{pmol} / \mathrm{l}) / \mathrm{TT}_{4}$ concentration $(\mathrm{nmol} / \mathrm{l}) \times 10$.

Although each animal served as its own control, for purposes of comparison, the normal ranges for hormonal analytes as determined by values 2 s. D. above and below the mean in 30 lean cats in our research colony were: $\mathrm{TT}_{4}(12-$ $29 \mathrm{nmol} / \mathrm{l}), \mathrm{TT}_{3}(0 \cdot 06-1 \cdot 1 \mathrm{nmol} / \mathrm{l}), \mathrm{FT}_{4}(15-40 \mathrm{pmol} / \mathrm{l})$, and $\mathrm{FT}_{4}$ fraction $\left(\mathrm{FFT}_{4}\right)(0 \cdot 05-0 \cdot 23 \%)$. The values demonstrated a parametric distribution.

\section{Serum TSH immunoassay}

The commercial canine TSH immunoassay (Immulite Canine TSH, Diagnostic Products Corporation Inc., (DPC) Los Angeles, CA, USA) was standardized for feline TSH using a standard curve of purified recombinant feline TSH prepared as described by Rayalam et al. $(2006 a, b)$. In brief, the protein concentration of the purified recombinant feline $\mathrm{TSH}$ (rfsTSH) standard was determined by bicinchoninic acid protein assay using bovine TSH as a protein standard. Purity of the recombinant hormone was established by densitometric analysis of a silver-stained PAGE. For rfTSH preparations in which this gravimetric analysis was performed in parallel with measurement in this commercial canine TSH assay, rfTSH was detected with $34 \cdot 0 \pm 6 \cdot 2 \%$ (mean \pm s.D.) efficiency. We noted that recombinant canine TSH prepared, expressed, and purified with the same techniques was detected with $73 \cdot 6 \%$ efficiency. The rfTSH standards diluted in the serum 'blank' provided in the commercial assay showed linearity with the provided canine TSH standards $(R=0.999)$ with an intercept indistinguishable from zero. Using this standardized assay, serum TSH concentrations were determined in nine animals during the lean and obese state. To facilitate comparison with other studies using this canine TSH assay to measure feline $\mathrm{TSH}$, the values directly derived from the canine standard curve (i.e. uncorrected for efficiency of detection of rfTSH) were reported. For comparison, one laboratory has reported immunoreactive TSH in normal cats as measured in the DPC canine TSH assay to be $0 \cdot 03-0 \cdot 11 \mathrm{ng} / \mathrm{ml}$ with a detection limit of $0.03 \mathrm{ng} / \mathrm{ml}$ and a median of $0.05 \mathrm{ng} / \mathrm{ml}$ (Moore et al. 2004).

\section{$\mathrm{FT}_{4}$ fraction by tracer equilibrium dialysis: effect of added NEFAs}

To directly evaluate the effect of specific NEFAs on serum binding of $\mathrm{T}_{4}$, a tracer dialysis procedure was used as described for dog serum (Ferguson \& Peterson 1992). In brief, customized Plexiglas chambers with dialysand and dialysate chamber volumes of $1 \mathrm{ml}$ were used. High specific activity ${ }^{125} \mathrm{I}_{-} \mathrm{T}_{4}$ was purchased from Perkin-Elmer (Wellesley, MA, USA) and added to a 5\% solution of BSA and pre-

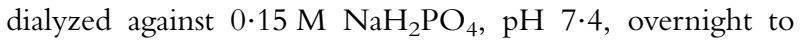
remove iodide. Pooled normal cat serum was used for these in vitro studies and was assayed to have $0.159 \mathrm{mEq} / 1$ nonesterified fatty acids. Stock solutions of sodium oleate and sodium palmitate (Sigma Chemical Co.) were prepared in $1 \%$ BSA solution at $300 \mathrm{mEq} / 1$ and, by dilution, to $100,60,30$, 
and $10 \mathrm{mEq} / 1$. Sera with added NEFAs were prepared by a $1: 100$ dilution of the stock, resulting in final concentrations of $0 \cdot 159,0 \cdot 259,0.459,0.759,1 \cdot 159$, and $3.159 \mathrm{mEq} / 1$, and allowed to pre-incubate $30 \mathrm{~min}$ at room temperature. Ten microliters of the pre-dialyzed tracer $(0 \cdot 1-0 \cdot 2 \mu \mathrm{Ci})$ were then added to the serum and incubated for $30 \mathrm{~min}$ at room temperature. One milliliter of serum and of the dialysis buffer was added to each side of the chamber, sealed, and allowed to dialyze for 16-24 h. The dialysate buffer was then subject to magnesium precipitation to remove residual iodide in the dialysate and $\mathrm{FT}_{4}$ fraction calculated as described previously (Ferguson \& Peterson 1992).

\section{Statistical analysis}

All data were analyzed using computer software (Prism software, GraphPad Software Inc, San Diego, CA, USA). The data are expressed as means \pm s.D. unless otherwise stated. The significance of differences of means was evaluated by paired $t$-test. Values of $P<0.05$ were considered significant.

\section{Results}

Body weight, fat mass, girth, and BMI were significantly higher between the lean and obese state (Table 1). Leptin increased from $327 \pm 17$ to $482 \pm 48(\mathrm{pmol} / 1 ; P<0 \cdot 004)$, as did NEFAs. They were $0.33 \pm 0.04 \mathrm{mEq} / 1$ in the lean state and $0.49 \pm 0.05 \mathrm{mEq} / 1$ in the obese state $(P<0.002)$.

$\mathrm{TT}_{4}, \mathrm{TT}_{3}$, and $\mathrm{FT}_{4}$ concentrations, and $\% \mathrm{FFT}_{4}$ are shown in Fig. 1A-D. Although $\mathrm{TT}_{4}$ trended to be higher in obese than lean cats $(P<0 \cdot 08)$, this was not significant. $\mathrm{TT}_{3}$ also did not change significantly with an increase in fat mass; however, $\mathrm{FT}_{4}$ was significantly higher in obese than lean cats $(P<0 \cdot 0001)$, as was $\mathrm{FFT}_{4}(P<0 \cdot 004)$. $\mathrm{FT}_{4}$ correlated positively and significantly with all indices of obesity (body weight, $P<0 \cdot 002$; \% body fat (BF), $P<0 \cdot 0001$, Fig. 2A; girth, $P<0 \cdot 0001$; and BMI, $P<0 \cdot 02)$. $\mathrm{FT}_{4}$ also correlated positively with NEFA $(P<0 \cdot 025$, Fig. 2B) and leptin $(P<0 \cdot 04) . \mathrm{TT}_{4}$ correlated positively and significantly with all indices of obesity (body weight, $P<0 \cdot 001 ; \%$ fat, $P<0 \cdot 02$; girth, $P<0.003$; and BMI, $P<0.03)$, as well as with leptin $(P<0.002)$ but not with NEFA. $\mathrm{TT}_{3}$ correlated positively with weight $(P<0 \cdot 004)$, girth $(P<0 \cdot 013)$, and BMI $(P<0 \cdot 04) . \mathrm{FFT}_{4}$ correlated significantly and linearly with NEFA concentration (Fig. 2C; $P<0 \cdot 002$ ).
Mean ( \pm S.D.) TSH concentration $(\mathrm{ng} / \mathrm{ml})$ measured in nine cats during the lean state was $0.038 \pm 0.016 \mathrm{ng} / \mathrm{ml}$, and in the obese state was $0 \cdot 048 \pm 0 \cdot 024 \mathrm{ng} / \mathrm{ml}$, an insignificant rise. All samples were above the lower limit of detection of $0 \cdot 01 \mathrm{ng} / \mathrm{ml}$ against the canine TSH standard.

When specific NEFAs were examined for effects of displacing tracer $\mathrm{T}_{4}$ from pooled cat serum, oleate and palmitate increased $\mathrm{FFT}_{4}$ at a concentration above $1 \mathrm{mEq} / 1$ (Fig. 3). This in vitro effect appears to confirm a direct inhibitory effect of common circulating NEFAs on $\mathrm{T}_{4}$ binding to cat serum proteins, an effect seen at NEFA concentrations observed in obese cats, and one which would account in significant part for the elevations in $\mathrm{FT}_{4}$ concentrations by direct dialysis seen in obese patients.

\section{Discussion}

The observation of an increase in $\mathrm{FT}_{4}$ in cats developing obesity is similar to those reported in a recent study of obese women. Serum concentrations of TSH, $\mathrm{T}_{4}, \mathrm{~T}_{3}$, and $\mathrm{FT}_{4}$ were observed to be elevated (Kozlowska \& Rosolowska-Huszcz 2004). This study did not see the $\mathrm{FFT}_{4}$ fall during weight loss and attributed it to potentially increased non-esterified fatty acids, although they were not measured, nor was $\mathrm{FT}_{4}$ measured by a dialysis procedure. However, while multiple studies have demonstrated a positive correlation between TSH and BMI, they generally have noted a negative association between $\mathrm{BMI}$ and $\mathrm{FT}_{4}$ concentrations, albeit with changes within normal range. It should be noted that non-dialysis techniques were used to estimate $\mathrm{FT}_{4}$ concentration (Knudsen et al. 2005).

Our studies of developing obesity in cats suggest that a primary alteration in thyroid function is an alteration of $\mathrm{FFT}_{4}$ induced by the increase in NEFAs, and that this effect can be mimicked in pooled cat serum by the addition of the exogenous NEFAs oleic or palmitic acid. It is possible that a larger sample size might have demonstrated a significant increase in $\mathrm{TT}_{4}$ and $\mathrm{TT}_{3}$, and it is notable that both correlated significantly with the obesity indices of weight, girth, and $\mathrm{BMI}$, and $\mathrm{TT}_{4}$ also correlated with BF and leptin. The lack of significant changes in $\mathrm{TT}_{3}$ or $\mathrm{TT}_{4}$ is inconsistent with studies in man, which have generally shown an increase in $T_{3}$ production and $\mathrm{rT}_{3}$ degradation rates, with no change in net $T_{4}$ production or degradation, suggesting an increase in the Type I $5^{\prime}$-deiodinase (D1) enzyme activity (Roti et al. 2000). Studies in the dog

Table 1 Body weight $(\mathrm{kg})$, body fat $(\%)$, girth $(\mathrm{m})$, and body mass index $\left(\mathrm{kg} / \mathrm{m}^{2}\right)$ in 21 neutered female adult cats before (lean) and after becoming obese (obese). Variances are s.D.

\begin{tabular}{|c|c|c|c|c|}
\hline & Body weight (kg) & Body fat $(\%)$ & Girth (m) & Body mass index $\left(\mathrm{kg} / \mathrm{m}^{2}\right)$ \\
\hline Lean & $4 \cdot 2 \pm 0 \cdot 5$ & $23 \cdot 6 \pm 6 \cdot 2$ & $0 \cdot 37 \pm 0 \cdot 04$ & $44 \cdot 3 \pm 6 \cdot 2$ \\
\hline Obese & $5 \cdot 0 \pm 0 \cdot 7^{+}$ & $36 \cdot 8 \pm 5 \cdot 9^{\dagger}$ & $0.43 \pm 0.01^{*}$ & $54 \cdot 7 \pm 7 \cdot 1^{+}$ \\
\hline
\end{tabular}

Significance when compared in paired analysis with same parameter in the lean state $* P<0 \cdot 004,{ }^{+} P<0 \cdot 0001$. 

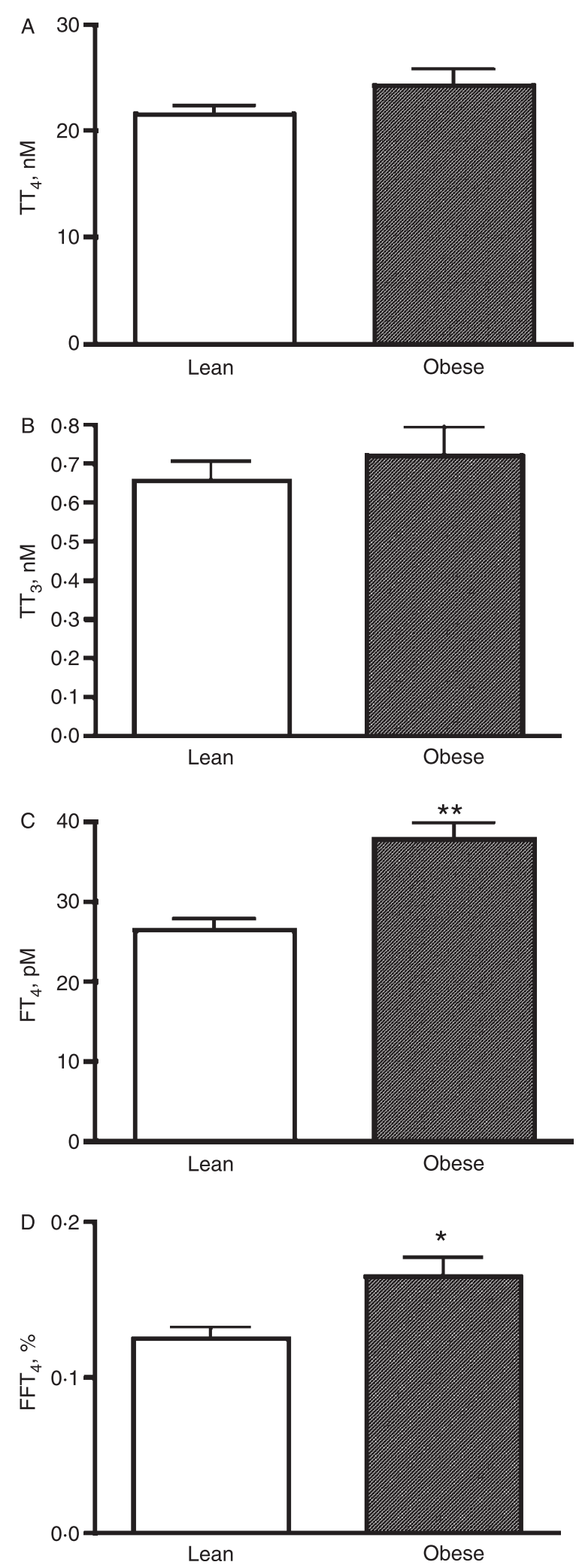

Journal of Endocrinology (2007) 194, 267-273 showed an increase in $T_{3}$, but no change in reverse $T_{3}$ concentrations (Daminet et al. 2003). Conversely, the Type II 5'deiodinase (D2) was shown to be decreased in white adipose tissue of obese human patients (Nauman et al. 1990).

Establishing cause and effect for the observed changes is difficult with this study alone. However, it should be noted that the tightest correlations to $\mathrm{FT}_{4}$ were with \% $\mathrm{BF}$ and between $\mathrm{FFT}_{4}$ and NEFAs (Fig. 2). Furthermore, the changes in the calculated $\mathrm{FFT}_{4}$ in vivo are made more plausible by the in vitro evidence that NEFAs can increase $\mathrm{FFT}_{4}$ at concentration ranges achieved during obesity.

TSH is a very sensitive marker of altered thyroid status in man with exponential increases or decreases with linear changes in $\mathrm{FT}_{4}$ concentrations. If the change in plasma NEFA concentration was the initial and sole effect, one would predict that $\mathrm{FT}_{4}$ would be transiently increased, TSH would suppress transiently, and then $\mathrm{TT}_{4}$ would fall, until $\mathrm{FT}_{4}$ normalized. However, to explain the results, it is necessary to postulate that there is a concomitant change in the sensitivity of the hypothalamus and/or pituitary to negative feedback. In cats progressing to the obese state, $\mathrm{FT}_{4}$ remained elevated, $\mathrm{TT}_{4}$ was unchanged (with a trend toward elevation, not depression), and TSH did not change, and in no case in which it was measured, was it undetectable as is observed in spontaneous hyperthyroidism. Measurement of serum TSH in additional cats might have uncovered a significant change in TSH, but TSH measurements were not initially planned because recombinant feline TSH was not yet available to standardize the canine assay.

We propose that obesity induces a relative state of $\mathrm{TH}$ resistance, either caused by the effect of leptin or by the effect of increased NEFA concentrations, or both. The diagnostic criterion for $\mathrm{TH}$ resistance is an elevated $\mathrm{FT}_{4}$ with a normal or elevated TSH concentration, and we believe that these observations are consistent with this criterion (Brucker-Davis et al. 1995, Larsen \& Davies 2003). Most often when TSH and $\mathrm{TH}$ concentrations are elevated in obese human subjects, they are still within the normal range (Reinehr \& Andler 2002, Michalaki et al. 2006, Nyrnes et al. 2006).

Accurate measurement of TSH is critical to the accurate interpretation of the physiological significance of the increased $\mathrm{FT}_{4}$ concentrations in obesity. This is the first report of the use of a commercially available canine TSH assay to measure serum feline TSH with documentation of detection efficiency of a feline TSH standard of known gravimetric purity. It is apparent that detection of feline TSH by the Immulite canine TSH assay is less complete (46\%) than that observed with recombinant canine TSH. We would note that the predicted normal range for this small sample of lean

Figure 1 Serum concentrations of total $T_{4}(A)$, total $T_{3}(B)$, direct dialysis free $\mathrm{T}_{4}\left(\mathrm{FT}_{4} ; \mathrm{C}\right)$, and calculated free fraction of $\mathrm{T}_{4}\left(\mathrm{FFT}_{4} ; \mathrm{D}\right)$ in 21 cats before (lean) and after becoming obese (obese). Error bars are s.D. Values with the same superscript letter differ significantly. Significance when compared in paired analysis with same parameter in the lean state: ${ }^{* *} P<0 \cdot 0001, * P<0 \cdot 004$. 

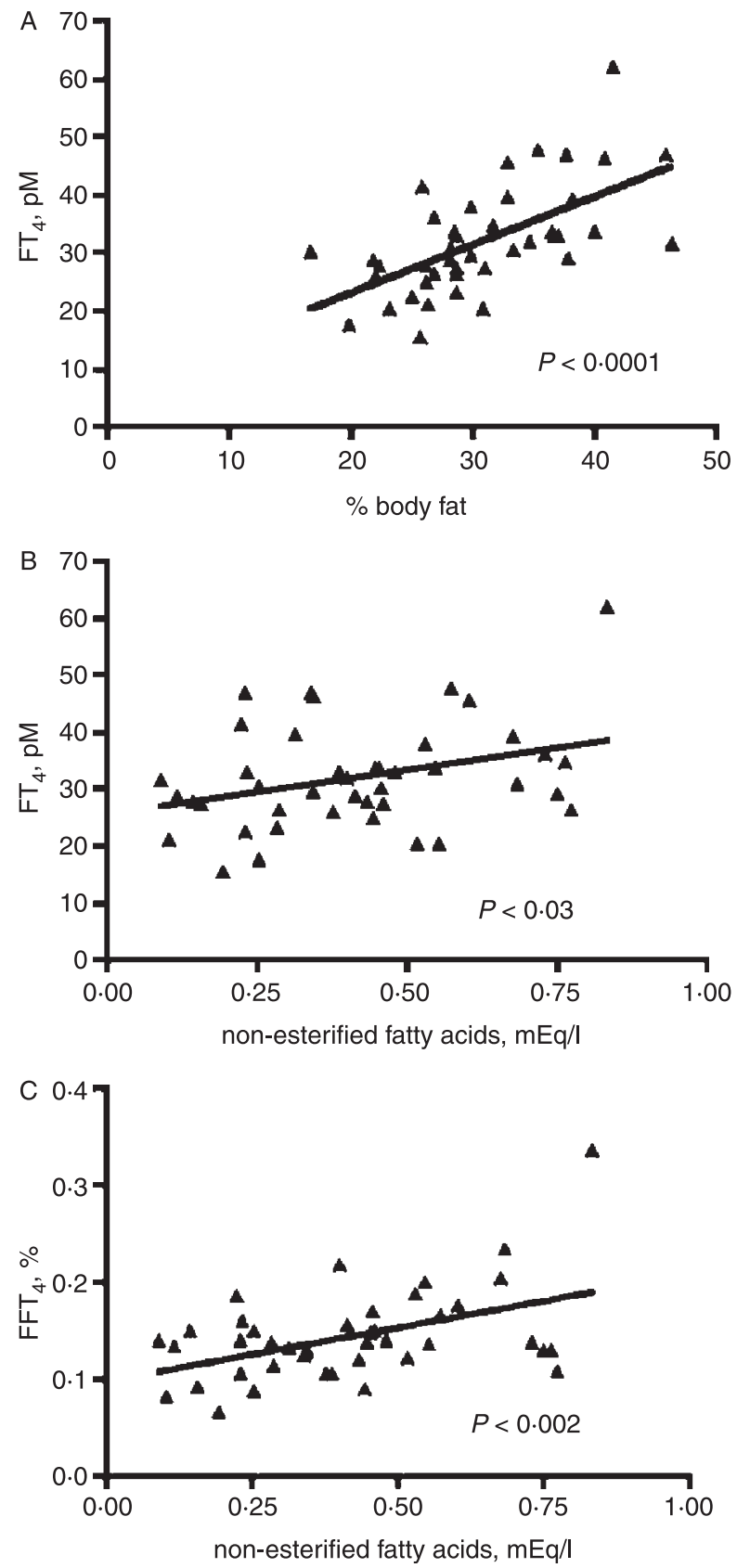

Figure 2 (A) Correlation between $\mathrm{FT}_{4}(\mathrm{pM})$ and body fat (\%) in 21 neutered female adult cats before and after becoming obese $\left(r^{2}=\right.$ $0 \cdot 38, P<0 \cdot 0001)$. (B) Correlation between $\mathrm{FT}_{4}(\mathrm{pM})$ and nonesterified fatty acids $(\mathrm{mEq} / \mathrm{l})$ in 21 neutered female adult cats before and after becoming obese $\left(r^{2}=0 \cdot 11, P<0 \cdot 03\right)$. (C) Correlation between $\mathrm{FFT}_{4}(\%)$ and nonesterified fatty acids $(\mathrm{mEq} / \mathrm{l})$ in 21 neutered female adult cats before and after becoming obese $\left(r^{2}=0 \cdot 22, P<0 \cdot 03\right)$.

cats would predict a normal range with $95 \%$ confidence limits for TSH of $0 \cdot 01-0 \cdot 21 \mathrm{ng} / \mathrm{ml}$, much closer to those observed in the normal $\operatorname{dog}(<0.5 \mathrm{ng} / \mathrm{ml})$ or human $(0.02-$ $0.32 \mathrm{ng} / \mathrm{ml}$, assuming $0.08 \mathrm{ng} /$ microunit bioactivity (Nyrnes

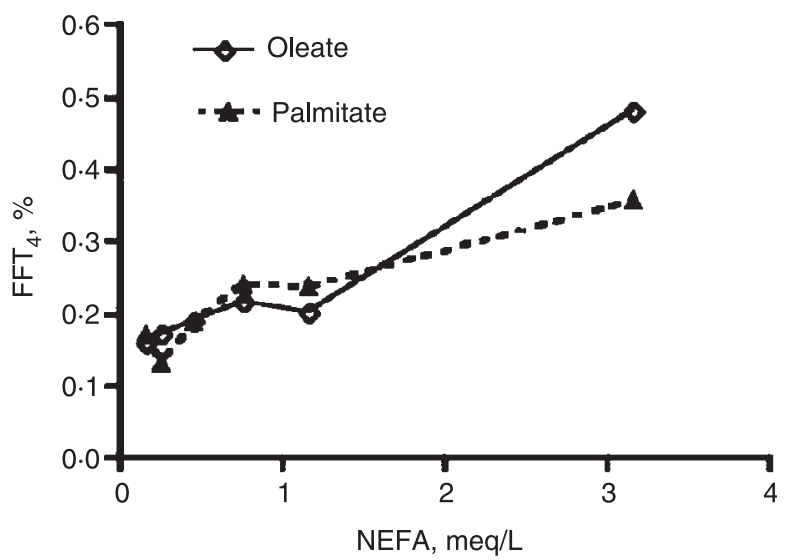

Figure 3 Effect of added oleic and palmitic acids on the displacement of ${ }^{125} \mathrm{I}-\mathrm{T}_{4}$ from pooled cat serum as reflected by the free $\mathrm{T}_{4}$ fraction (\%) determined by equilibrium dialysis in vitro. Points represent the average three replicate dialyses per concentration.

et al. 2006). Higher concentrations would be more consistent with the concentration range observed for the IC50s for bovine TSH displacement of ${ }^{125}$ I-bovine TSH from the feline TSH receptor $(0.19 \mathrm{nmol} / 1$ or $5.5 \mathrm{ng} / \mathrm{ml}$; Nguyen et al. 2002) and for recombinant feline TSH stimulation of adenylate cyclase in cells expressing the human TSH receptor $(10.7 \mathrm{vs} 4.9 \mathrm{ng} / \mathrm{ml}$ for bovine TSH; Rayalam et al. $(2006 a, b)$.

The current study is the first to identify a relationship between the rise in $\mathrm{FT}_{4}$ associated with obesity being linked to the rise in NEFA. There may be several reasons that the elevation of $\mathrm{FT}_{4}$ had not previously been identified. First with the exception of one study of dogs (Daminet et al. 2003), non-dialysis analog procedures for determining $\mathrm{FT}_{4}$ have generally been employed. Analog $\mathrm{FT}_{4}$ assays are not as likely to distinguish the effect of low-affinity inhibitors of serum TH binding such as NEFAs (Nelson et al. 2005). In studies of healthy euthyroid dogs, a good correlation between dialysis and analog $\mathrm{FT}_{4}$ immunoassays has been observed (Schachter et al. 2004, Martin et al. 2006). However, this correlation tends to degrade when sick animals are evaluated suggesting that these assays may be incapable of discerning the effects of weak circulating weak inhibitors of serum TH binding (Schachter et al. 2004).

Secondly, the current study evaluated the same cat as it progressed from the lean to the obese state. It is also worth noting that, for most of the prior studies, $\mathrm{FT}_{4}$ and, when it was measured, TSH generally remained within the normal range. Given intersubject variation, this pathophysiological mechanism may have been obscured when lean and obese groups were distinct populations.

Thirdly, cats are a species that have very low concentrations of specific serum thyroid-hormone-binding proteins such as thyroxine-binding globulin (TBG), which dominate serum binding of $\mathrm{T}_{4}$ in primates (Refetoff et al. 1970). As such, changes in NEFA concentrations may have a greater tendency to impact $\mathrm{TH}$ binding in serum. Given the close similarity of the composition of serum thyroid-hormone-binding proteins in 
dogs and cats, it is interesting to compare the results in cats with a study of separate groups of lean and obese laboratory beagles (Daminet et al. 2003). The obese dogs had significantly elevated serum $\mathrm{TT}_{4}$ and $\mathrm{T}_{3}$ concentrations, but neither $\mathrm{TSH}$ nor $\mathrm{FT}_{4}$, measured by equilibrium dialysis, was increased. The investigators suggest that the $T_{4}$ increase in obesity could be the result of an increase in the serum concentration of thyroid-hormone-binding proteins, specifically TBG. However, they also show that the maximum serum $\mathrm{T}_{4}$ response following $\mathrm{TSH}$ administration was not different. From this, one would conclude that the thyroid functional reserve is unchanged in obesity, and the results are more suggestive of a change in hypothalamic-pituitary set point than that of a change in binding protein capacity (Daminet et al. 2003).

Aside from the hypothesis of $\mathrm{TH}$ resistance associated with increased NEFA concentrations, the increase in $\mathrm{FT}_{4}$ observed in the cats during the obese phase of this study could be the result of other factors changing the hypothalamic-pituitary set point for negative feedback. Some studies have demonstrated an increase in free $\mathrm{TH}$ as well as TSH concentrations in humans (Duntas et al. 1991). TSH increases in another study were shown to be proportional to BMI (Nyrnes et al. 2006). In support of this theory is the fact that in obesity, nuclear $T_{3}$ receptors are decreased in number (Burman et al. 1980) and, presumably, the negative feedback between the TSH and the peripheral THs and TSH secretion, mediated by the TR $\beta$ nuclear thyroid receptor of the hypothalamus and pituitary, is decreased. As demonstrated in the rat, some compounds may inhibit binding of $\mathrm{TH}$ to $\operatorname{TR} \beta$ without affecting $\operatorname{TR} \alpha$, resulting in tissue hyperthyroidism where the latter receptor subtype exists (Zoeller et al. 2005). Our study of cats showed no significant increase in TSH concentration with obesity. This does not preclude the presence of an altered set point for negative feedback as a normal TSH concentration is inappropriately high in the face of the elevation of $\mathrm{FT}_{4}$ concentration. In the obese dog, the elevated baseline $\mathrm{T}_{4}$ but identical maximal response of $\mathrm{T}_{4}$ to TSH also suggests that there was a change in hypothalamicpituitary set point, albeit with a normal baseline TSH concentration (Daminet et al. 2003). It has been suggested that measurement of the serum response of TSH to administered TRH would be useful to ascertain whether pituitary sensitivity is altered in obesity. However, at least in one study of obese patients, the response of TSH to i.v. TRH was not altered (Duntas et al. 1991). Future studies will be necessary to address this question in the cat.

Leading theories suggest that leptin and the adrenergic neurotransmitters are key regulators of the hypothalamicpituitary-thyroid axis. When human subjects were sampled every $10 \mathrm{~min}$ for leptin and TSH concentrations, there was a linear relationship between the 24-h leptin and TSH, with a significantly higher 24-h rate in obese but a lower rate in fasted patients. Indeed, leptin has been shown to also correlate with thyroid volume (Ghizzoni et al. 2001). However, leptin and TSH concentrations both correlate with the degree of obesity, obscuring whether there is a cause-effect relationship. Reduced dopamine 2 (D2) receptors in the brain have been observed in obesity (Pinkney et al. 1998, Kok et al. 2005), and production of $\mathrm{TSH}$ is also regulated by transmitters and hormones, which regulate body weight and satiety, such as the neurotransmitters neuropeptide Y, $\boldsymbol{\alpha}$-melanocyte-stimulating hormone, and the agouti-related peptide, which interact with hypothalamic TRH neurons (Fekete et al. 2000, 2001, 2002, Guo et al. 2004).

In summary, the development of obesity in the cat is associated with a significant increase in $\mathrm{FT}_{4}$ within the normal reference range, a change that correlated with the increase in plasma NEFA concentrations. We propose that the effect of obesity on $\mathrm{FT}_{4}$ is primary as $\mathrm{FT}_{4}$ and $\mathrm{FFT}_{4}$ were most tightly correlated with BF and plasma NEFA concentrations. However, the set point for negative feedback on TSH secretion must also be altered as $\mathrm{TT}_{4}$ and $\mathrm{TSH}$ concentrations remained unchanged, and $\mathrm{TT}_{4}$ did not fall inversely with the rise in $\mathrm{FT}_{4}$. Furthermore, we were able to demonstrate that the in vitro addition of NEFAs led to a significant increase of the $\mathrm{FT}_{4}$ fraction. It is difficult to ascertain whether the cats developed a change in their tissue thyroid status upon the development of obesity.

Further investigation into the cellular thyroid status will be necessary to establish cause and effect in this animal model of obesity. It will require the measurement of markers of TH action in peripheral tissue such as muscle or adipose tissue to evaluate whether there might be tissue-specific changes in the TH's action resulting from the increased serum $\mathrm{FT}_{4}$ concentration.

\section{Funding}

This study was supported in part through the University of Georgia Veterinary Medical Alumni Fund. The authors declare that there is no conflict of interest that would prejudice the impartiality of this scientific work.

\section{References}

Bray GA, Fisher DA \& Chopra IJ 1976 Relation of thyroid hormones to body-weight. Lancet 1 1206-1208.

Brucker-Davis F, Skarulis MC, Grace MB, Benichou J, Hauser P, Wiggs E \& Weintraub BD 1995 Genetic and clinical features of 42 kindreds with resistance to thyroid hormone. Annals of Internal Medicine 123 572-583.

Burman KD, Latham KR, Djuh YY, Smallridge RC, Tseng YC, Lukes YG, Maunder R \& Wartofsky L 1980 Solubilized nuclear thyroid hormone receptors in circulating human mononuclear cells. Journal of Clinical Endocrinology and Metabolism 51 106-116.

Daminet S, Jeusette I, Duchateau L, Diez M, Van de Maele I \& De Rick A 2003 Evaluation of thyroid function in obese dogs and in dogs undergoing a weight loss protocol. Journal of Veterinary Medicine. A. Physiology, Pathology, Clinical Medicine 50 213-218.

Davidson MB \& Chopra IJ 1979 Effect of carbohydrate and noncarbohydrate sources of calories on plasma 3,5,3'-triiodothyronine concentrations in man. Journal of Clinical Endocrinology and Metabolism 48 577-581.

Duntas L, Hauner H, Rosenthal J \& Pfeiffer EF 1991 Thyrotropin releasing hormone (TRH) immunoreactivity and thyroid function in obesity. International Journal of Obesity 15 83-87.

Edupuganti S, Svec F, Bao W, Srinivasan SR \& Berenson GS 1997 Thyroid function in children with different lipoprotein profiles: observations in a biracial (black/white) population - the Bogalusa Heart Study. American Journal of the Medical Sciences 313 80-84. 
Fekete C, Legradi G, Mihaly E, Huang QH, Tatro JB, Rand WM, Emerson CH \& Lechan RM 2000 Alpha-melanocyte-stimulating hormone is contained in nerve terminals innervating thyrotropin-releasing hormonesynthesizing neurons in the hypothalamic paraventricular nucleus and prevents fasting-induced suppression of prothyrotropin-releasing hormone gene expression. Journal of Neuroscience 20 1550-1558.

Fekete C, Kelly J, Mihaly E, Sarkar S, Rand WM, Legradi G, Emerson CH \& Lechan RM 2001 Neuropeptide Y has a central inhibitory action on the hypothalamic-pituitary-thyroid axis. Endocrinology 142 2606-2613.

Fekete C, Sarkar S, Rand WM, Harney JW, Emerson CH, Bianco AC \& Lechan RM 2002 Agouti-related protein (AGRP) has a central inhibitory action on the hypothalamic-pituitary-thyroid (HPT) axis; comparisons between the effect of AGRP and neuropeptide Yon energy homeostasis and the HPT axis. Endocrinology 143 3846-3853.

Ferguson DC \& Peterson ME 1992 Serum free and total iodothyronine concentrations in dogs with hyperadrenocorticism. American Journal of Veterinary Research 53 1636-1640.

Ghizzoni L, Mastorakos G, Ziveri M, Furlini M, Solazzi A, Vottero A \& Bernasconi S 2001 Interactions of leptin and thyrotropin 24-hour secretory profiles in short normal children. Journal of Clinical Endocrinology and Metabolism 86 2065-2072.

Glass A \& Kushner J 1996 Obesity, nutrition, and the thyroid. Endocrinology 6 392-403.

Guo F, Bakal K, Minokoshi Y \& Hollenberg AN 2004 Leptin signaling targets the thyrotropin-releasing hormone gene promoter in vivo. Endocrinology 145 2221-2227.

Hoenig M, Hall G, Ferguson D, Jordan J, Henson M, Johnson K \& O’Brien TD 2000 A feline model of experimentally induced islet amyloidosis. American Journal of Pathology 157 2143-2150.

Hoenig M, Wilkins C, Holson JC \& Ferguson DC 2003 Effects of obesity on lipid profiles in neutered male and female cats. American Journal of Veterinary Research 64 299-303.

Hoenig M, Thomaseth K, Waldron M \& Ferguson DC 2007a Fatty acid turnover, substrate oxidation, and heat production in lean and obese cats during the euglycemic hyperinsulinemic clamp. Domestic Animal Endocrinology 32 329-338.

Hoenig M, Thomaseth K, Waldron M \& Ferguson DC $2007 b$ Insulin sensitivity, fat distribution, and adipocytokine response to different diets in lean and obese cats before and after weight loss. American Journal of Physiology. Regulatory, Integrative and Comparative Physiology 292 R227-R234.

Iacobellis G, Ribaudo MC, Zappaterreno A, Iannucci CV \& Leonetti F 2005 Relationship of thyroid function with body mass index, leptin, insulin sensitivity and adiponectin in euthyroid obese women. Clinical Endocrinology 62 487-491.

Knudsen N, Laurberg P, Rasmussen LB, Bulow I, Perrild H, Ovesen L \& Jorgensen T 2005 Small differences in thyroid function may be important for body mass index and the occurrence of obesity in the population. Journal of Clinical Endocrinology and Metabolism 90 4019-4024.

Kok P, Roelfsema F, Langendonk JG, Frolich M, Burggraaf J, Meinders AE \& Pijl H 2005 High circulating thyrotropin levels in obese women are reduced after body weight loss induced by caloric restriction. Journal of Clinical Endocrinology and Metabolism 90 4659-4663.

Kozlowska L \& Rosolowska-Huszcz D 2004 Leptin, thyrotropin, and thyroid hormones in obese/overweight women before and after two levels of energy deficit. Endocrine 24 147-153.

Larsen PR \& Davies TF 2003 Hypothyroidism and thyroiditis. In Williams Textbook of Endocrinology, edn 10, pp 441-442. Eds PR Lasen, HM Kronenberg, SM Melmed \& KS Polonsky. Philadelphia: Saunders.

Martin LJ, Siliart B, Dumon HJ \& Nguyen PG 2006 Hormonal disturbances associated with obesity in dogs. Journal of Animal Physiology and Animal Nutrition 90 355-360.

Matzen LE, Kvetny J \& Pedersen KK 1989 TSH, thyroid hormones and nuclear-binding of $\mathrm{T}_{3}$ in mononuclear blood cells from obese and nonobese women. Scandinavian Journal of Clinical and Laboratory Investigation 49 249-253.

Michalaki MA, Vagenakis AG, Leonardou AS, Argentou MN, Habeos IG, Makri MG, Psyrogiannis AI, Kalfarentzos FE \& Kyriazopoulou VE 2006 Thyroid function in humans with morbid obesity. Thyroid 16 73-78.
Moore KL, Syme H \& Groves E 2004 Use of endogenous thyroid stimulating hormone measurement to diagnose hyperthyroidism in cats with chronic renal failure. British Small Animal Veterinary Association Scientific Proceedings 521 (abst. 32).

Nauman A, Nauman J, Sypniewska G, Fiedorowicz K \& Bielecki K 1990 Regulation of triiodothyronine levels in fatty tissue in obese patients. Wiadomosci Lekarskie 43 427-432.

Nelson JC, Wang R, Asher DT \& Wilcox RB 2005 Underestimates and overestimates of total thyroxine concentrations caused by unwanted thyroxine-binding protein effects. Thyroid 15 12-15.

Nguyen LQ, Arseven OK, Gerber H, Stein BS, Jameson JL \& Kopp P 2002 Cloning of the cat TSH receptor and evidence against an autoimmune etiology of feline hyperthyroidism. Endocrinology 143 395-402.

Nyrnes A, Jorde R \& Sundsfjord J 2006 Serum TSH is positively associated with BMI. International Journal of Obesity 30 100-105.

Oppenheimer JH, Schwartz HL, Lane JT \& Thompson MP 1991 Functional relationship of thyroid hormone-induced lipogenesis, lipolysis, and thermogenesis in the rat. Journal of Clinical Investigation 87 125-132.

Peterson ME, Kintzer PP, Cavanagh PG, Fox PR, Ferguson DC, Johnson GF \& Becker DV 1983 Feline hyperthyroidism: pretreatment clinical and laboratory evaluation of 131 cases. Journal of American Veterinary Medical Association 183 103-110.

Pinkney JH, Goodrick SJ, Katz J, Johnson AB, Lightman SL, Coppack SW \& Mohamed-Ali V 1998 Leptin and the pituitary-thyroid axis: a comparative study in lean, obese, hypothyroid and hyperthyroid subjects. Clinical Endocrinology 49 583-588.

Rayalam S, Eizenstat LD, Hoenig M \& Ferguson DC 2006a Cloning and sequencing of feline thyrotropin (fTSH): heterodimeric and yoked constructs. Domestic Animal Endocrinology 30 203-217.

Rayalam S, Eizenstat LD, Davis RR, Hoenig M \& Ferguson DC 2006b Expression and purification of feline thyrotropin (fTSH): immunological detection and bioactivity of heterodimeric and yoked glycoproteins. Domestic Animal Endocrinology 30 185-202.

Refetoff S, Robin NI \& Fang VS 1970 Parameters of thyroid function in serum of 16 selected vertebrate species: a study of PBI, serum $\mathrm{T}_{4}$, free $\mathrm{T}_{4}$, and the pattern of $\mathrm{T}_{4}$ and $\mathrm{T}_{3}$ binding to serum proteins. Endocrinology 86 793-805.

Reinehr T \& Andler W 2002 Thyroid hormones before and after weight loss in obesity. Archives of Disease in Childhood 87 320-323.

Roti E, Minelli R \& Salvi M 2000 Thyroid hormone metabolism in obesity. International Journal of Obesity and Related Metabolic Disorders 24 (Suppl 2) S113-S115.

Sari R, Balci MK, Altunbas H \& Karayalcin U 2003 The effect of body weight and weight loss on thyroid volume and function in obese women. Clinical Endocrinology 59 258-262.

Schachter S, Nelson RW, Scott-Moncrieff C, Ferguson DC, Montgomery T, Feldman EC, Neal L \& Kass PH 2004 Comparison of serum-free thyroxine concentrations determined by standard equilibrium dialysis, modified equilibrium dialysis, and 5 radioimmunoassays in dogs. Journal of Veterinary Internal Medicine 18 259-264.

Silva JE 1995 Thyroid hormone control of thermogenesis and energy balance. Thyroid 5 481-492.

Stichel H, l'Allemand D \& Gruters A 2000 Thyroid function and obesity in children and adolescents. Hormone Research 54 14-19.

Tobias S \& Labato MA 2001 Identifying and managing feline congenital hypothyroidism. Veterinary Medicine 96 719-726.

Vettor R 2005 The metabolic actions of thyroid hormone and leptin: a mandatory interplay or not? Diabetologia 48 621-623.

Zoeller RT, Bansal R \& Parris C 2005 Bisphenol-A, an environmental contaminant that acts as a thyroid hormone receptor antagonist in vitro, increases serum thyroxine, and alters RC3/neurogranin expression in the developing rat brain. Endocrinology 146 607-612.

Received in final form 19 April 2007
Accepted 9 May 2007

Made available online as an Accepted Preprint 15 May 2007 